\title{
Silicone oil removal. I. The effect on the complications of silicone oil
}

\author{
A G CASSWELL AND Z J GREGOR
}

From Moorfields Eye Hospital, City Road, London EC1V 2PD

SUMMARY The results of a retrospective study of the effects of silicone oil removal from 85 eyes in 85 patients are reported. Pars plana vitrectomy and fluid/silicone oil exchange had been undertaken for retinal detachments associated with giant retinal tears or with proliferative vitreoretinopathy in all cases. Clinically significant cataract developed in $60 \%$ of lenses that were clear at the time of oil removal, and $85 \%$ of pre-existing lens opacities progressed. Removal of oil from 19 eyes with uncontrollable glaucoma was combined with drainage surgery in 14 eyes. Postoperatively the intraocular pressure was controlled in 13 . Corneal decompensation either improved or was unchanged in eight out of nine patients after silicone oil removal, and three patients had penetrating keratoplasty and maintained a clear corneal graft. Patients who did not have glaucoma or keratopathy at the time of silicone oil removal did not develop these complications.

Silicone oil has been used in the treatment of complex retinal detachments for many years. ${ }^{1}$ However, many authors have reported postoperative anterior segment complications, such as cataract, glaucoma, and keratopathy even after successful reattachment of the retina. ${ }^{2-6}$ The possibility of a toxic effect of silicone oil on the retina remains controversial..$^{7-11}$

When silicone oil has been used in conjunction with vitrectomy, it can subsequently be easily removed via the pars plana in phakic eyes or via the limbus in aphakic eyes. It has been suggested that many complications may be prevented or their progression arrested when the silicone oil is removed a few weeks or months after surgery,,$^{12}$ but there are few reports detailing the effects of removing it either as a prophylactic measure or as part of the management of established complications. ${ }^{.1-16}$

The purpose of this study was to assess the effects of silicone oil removal on the anterior segment complications associated with its use. Peroperative and postoperative complications associated with silicone oil removal are reported in a separate communication. ${ }^{17}$

\section{Patients and methods}

The hospital records of 92 consecutive patients who Correspondence to Z J Gregor, FRCS. had undergone silicone oil removal were reviewed. All patients, under the care of five vitreoretinal surgeons at Moorfields Eye Hospital, presented with retinal detachments associated with giant retinal tears or proliferative vitreoretinopathy and were treated by vitrectomy and fluid/silicone oil exchange. Patients with giant retinal tears and proliferative retinopathy were chosen because they represent the commonest indication for the use of silicone oil at this hospital. Patients underwent pars plana vitrectomy combined with epiretinal membrane dissection where appropriate and cryotherapy with scleral buckling as previously described. ${ }^{131819}$

Many patients, particularly those with proliferative vitreoretinopathy, had undergone multiple surgical procedures before silicone oil injection. After silicone oil exchange, but prior to its removal, further procedures were carried out in 25 patients. Supplementary photocoagulation of the peripheral retina was undertaken in eight, additional cryotherapy in two, and cryotherapy with scleral buckling in six. Epiretinal membrane dissection and silicone oil 'top-up' was required in four. One patient required the insertion of an anterior chamber drainage tube for intractable glaucoma. Anterior chamber paracentesis was performed in four aphakic patients in whom oil completely filled the anterior chamber, giving rise to markedly raised intraocular pressure. 

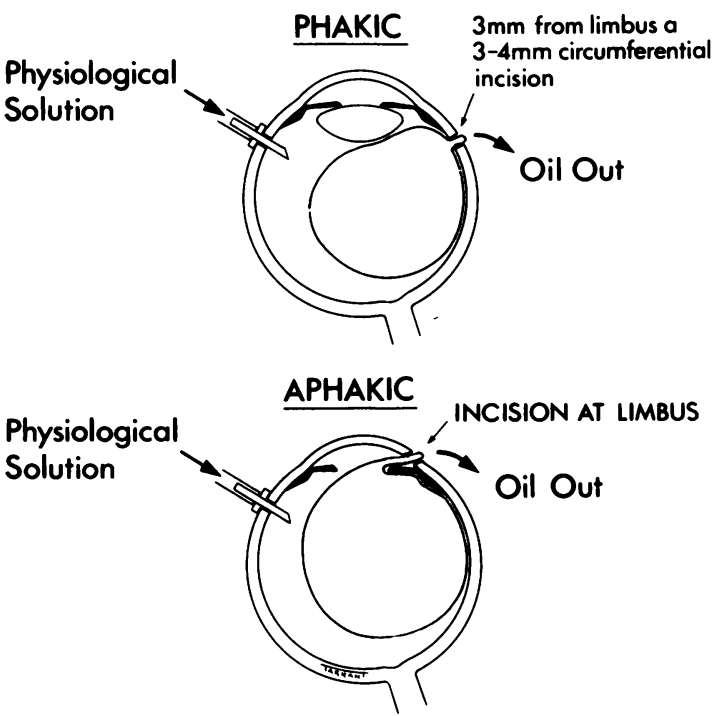

Fig. 1 Method of removal of silicone oil.

Many patients underwent silicone oil removal within one to three months to prevent the progression of lens opacities or development of glaucoma and keratopathy. Patients with uncontrollable glaucoma or keratopathy underwent silicone oil removal as part of the management of these complications.

Cataract was defined as progressive lens opacities documented on serial clinical examination. The presence of cataract alone was not an indication for removal of the silicone oil. Glaucoma was defined as intraocular pressure persistently greater than 30 $\mathrm{mmHg}$ on full medical treatment. Keratopathy ranged from corneal epithelial oedema at its earliest stage to stromal oedema, band keratopathy, and/or stromal thinning in more advanced cases.

The technique of silicone oil removal was that described by Leaver and Lean ${ }^{19}$ (Fig. 1). In some patients oil removal was combined with other procedures including lensectomy, trabeculectomy, aqueous drainage tube, or penetrating keratoplasty. Additional cryotherapy, scleral buckling, and/or epiretinal membrane dissection was undertaken at the time of oil removal if there appeared to be peripheral retinal detachment or persistent epiretinal traction.

Fundi were examined by indirect ophthalmoscopy at the end of the procedure in order to establish that the retina remained attached and that no large silicone oil bubbles remained in the vitreous cavity. A subconjunctival injection of antibiotics and steroids was given in each case.

Those patients with secondary glaucoma underwent removal of silicone oil when the intraocular pressure became uncontrollable medically. If extensive synechiae at the peripheral anterior chamber angle were present, silicone oil removal was combined with a trabeculectomy or insertion of an anterior chamber drainage tube.

Patients with keratopathy underwent removal of silicone oil when corneal oedema had progressed to the extent of causing marked reduction of visual acuity.

\section{Results}

Of the 92 hospital records reviewed seven were excluded because of insufficient documentation. Of the remaining 85 eyes 59 had giant retinal tears, and 26 patients had proliferative vitreoretinopathy (PVR); these included five patients with PVR who had previously had penetrating trauma.

The duration of follow-up after removal of silicone oil ranged from three to 60 months (mean 18 months).

\section{CATARACT}

The effect of removing silicone oil on the lens was studied in patients who were phakic at the time of oil removal and had at least six months' follow-up postoperatively. Twenty eight eyes were already aphakic when the oil was injected, and six underwent lens extraction at the time of oil removal. Of the 51 eyes which remained phakic after oil removal 16 developed retinal redetachment and were excluded. A further three patients were excluded with a followup of less than six months, leaving 32 for analysis (Table 1). Eleven had clear lenses at the time of oil removal, and, of these, five remained clear at six months and six developed lens opacities. Twenty one already had lens opacities at the time of oil removal, and in 18 the lens opacities increased. This last group included five with lens opacities limited to early vesicular subcapsular opacities which cleared completely immediately after oil removal but recurred and progressed in each case after several weeks. Seven patients underwent cataract extraction during the period of follow-up.

Table 1 Lens clarity following silicone oil removal in patients with attached retinae

\begin{tabular}{|c|c|c|c|c|c|}
\hline & \multirow[b]{2}{*}{$\begin{array}{l}\text { Total } \\
\text { eyes }\end{array}$} & \multicolumn{2}{|c|}{ Unchanged } & \multicolumn{2}{|c|}{$\begin{array}{l}\text { Increasing } \\
\text { lens opacities }\end{array}$} \\
\hline & & $\begin{array}{l}\text { No. of } \\
\text { eyes }\end{array}$ & $\begin{array}{l}\text { Oil in situ } \\
\text { (weeks) }\end{array}$ & $\begin{array}{l}\text { No. of } \\
\text { eyes }\end{array}$ & $\begin{array}{l}\text { Oil in situ } \\
\text { (weeks) }\end{array}$ \\
\hline Clear & 11 & 5 & $5 \cdot 6$ & 6 & $6 \cdot 3$ \\
\hline Opacities & 21 & 3 & $6 \cdot 3$ & 18 & $10 \cdot 6$ \\
\hline
\end{tabular}

Minimum follow-up six months. 
The relationship between the length of time that the oil was in situ and the development of lens opacities is shown in Table 1 . The mean length of time that the oil was in situ in eyes in which the lenses remained clear was 5.6 weeks, whereas in those which subsequently developed opacities it was $6 \cdot 3$ weeks. For patients whose pre-existing lens opacities did not progress the oil was in situ for a mean of $6 \cdot 3$ weeks, while for those who developed progressive changes the oil was in the eye for 10.6 weeks on average. No patient retained a clear lens if the oil remained in situ for more than 10 weeks.

Statistical analysis showed that eyes which developed lens opacities or in which lens opacities progressed had had silicone oil in situ for longer than those in which the lens status remained unchanged $(p=0.052)$. Logistic regression analysis showed that the length of time that the oil was in situ had a significant effect on the probability of developing increasing lens opacities and that, when that was taken into account, the lens clarity at the time of silicone oil removal had little effect on the chance of progression.

\section{GLAUCOMA}

Nineteen patients underwent removal of silicone oil as part of the treatment of otherwise uncontrollable glaucoma. Although the follow-up ranged from three months to 36 months (mean 15 months), only two patients had a follow-up of less than one year. Fifteen patients were aphakic and four were phakic. Of the four phakic patients a globule of oil was present in the anterior chamber in three. The mean duration of oil tamonade was 20 weeks. The intraocular pressure was raised from the time of silicone oil injection in eight patients, and the remaining 11 patients developed glaucoma between six and 20 months.

After oil removal without an additional drainage procedure the intraocular pressure was controlled by medical treatment alone in three patients and remained uncontrolled in two (Table 2). One of the latter patients required a further injection of silicone oil after developing a retinal detachment. Of the nine patients who underwent trabeculectomy at or shortly

Table 2 Results following oil removal in patients with uncontrolled glaucoma

\begin{tabular}{llll}
\hline Treatment & $\begin{array}{l}\text { IOP } \\
\text { controlled } \\
<21 \mathrm{mmHg}\end{array}$ & $\begin{array}{l}\text { IOP } \\
21-30 \mathrm{mmHg}\end{array}$ & $\begin{array}{l}\text { IOP } \\
>30 \mathrm{mmHg} \\
\text { orfield loss }\end{array}$ \\
\hline Medical (5) & 3 & 0 & 2 \\
Trabeculectomy (9) & 4 & 1 & 4 \\
Tube (5) & 2 & 1 & 2 \\
Total (19) & 9 & 2 & 8 \\
\hline
\end{tabular}

Mean follow-up of 15 months. after oil removal the intraocular pressure was controlled in four, was moderately raised in one (24 $\mathrm{mmHg}$ ), and in excess of $29 \mathrm{mmHg}$ in four. Five patients were treated initially with the insertion of a silicone tube draining aqueous from the anterior chamber to a surrounding silicone explant. This was sufficient to control the intraocular pressure in two patients initially (one subsequently required cyclocryotherapy). In one patient the intraocular pressure remained moderately elevated $(24 \mathrm{mmHg})$ and in two patients the intraocular pressure was uncontrolled ( $>30 \mathrm{mmHg}$ ).

Of the 66 patients without raised intraocular pressure at the time of oil removal (at 3-183 weeks with a mean of 15.0 weeks) five were found to have raised intraocular pressure following silicone oil removal. Of these patients one had congenital glaucoma, two developed raised pressure after a further injection of silicone oil for retinal redetachment and were controlled medically, and one developed mildly elevated intraocular pressure (24 $\mathrm{mmHg}$ ) while the oil was in situ. Only one patient developed raised intraocular pressure following silicone oil removal; there was no other obvious predisposing cause and the intraocular pressure was controlled medically.

\section{KERATOPATHY}

Keratopathy was present in 11 eyes, nine aphakic and two phakic, and included five with glaucoma. The silicone oil was in situ for 16 to 240 weeks (mean 88 weeks) for patients with corneal problems alone and 16-60 weeks (mean 32 weeks) for patients with both glaucoma and keratopathy. A penetrating keratoplasty was required in two eyes at the time of silicone oil removal and in both patients the corneae remained clear at six months. In the nine remaining eyes there was an improvement of the corneal oedema in six. Four with coexistent glaucoma recovered a completely clear cornea and a gradual clearing of the central corneal oedema took place over several months in two. Corneal oedema was

Table 3 Corneal clarity following oil removal

\begin{tabular}{|c|c|c|c|c|}
\hline & \multicolumn{4}{|c|}{ Outcome at 3 months } \\
\hline & $\begin{array}{l}\text { Clear } \\
\text { cornea }\end{array}$ & $\begin{array}{l}\text { Less } \\
\text { corneal } \\
\text { oedema }\end{array}$ & $\begin{array}{l}\text { Un- } \\
\text { changed }\end{array}$ & $\begin{array}{l}\text { Decom- } \\
\text { pensated }\end{array}$ \\
\hline $\begin{array}{l}\text { Corneal oedema at removal } \\
\text { (total 9) }\end{array}$ & $4^{*}$ & $2 \dagger$ & 2 & $1 \ddagger$ \\
\hline $\begin{array}{l}\text { Corneal graft at removal } \\
\quad(\text { total 2) }\end{array}$ & 2 & & & \\
\hline
\end{tabular}


unchanged in two eyes at six months following oil removal. Finally, one cornea became decompensated immediately after surgery and subsequently maintained a clear graft after penetrating keratoplasty (Table 3 ).

In the remaining 74 eyes in which there was no keratopathy at the time of oil removal no evidence of corneal decompensation occurred. The oil had remained in these eyes for 3-88 weeks (mean 11.8 weeks). The majority were phakic (55) while the oil was in situ, though 19 were aphakic and three phakic eyes had oil in the anterior chamber.

\section{Discussion}

The considerable controversy on the question of the complications of silicone oil has led to some retinal surgeons abandoning its use. ${ }^{211}$ The principal complications in the anterior segment are cataract occurring in $49-100 \%$ of eyes, ${ }^{2321}$ glaucoma in $11-33 \%,{ }^{319}$ and keratopathy in $11-44 \% .{ }^{3+22}$ Although inert gases have provided an alternative form of internal tamponade ${ }^{23}$ the use of silicone oil in combination with closed intraocular surgical techniques has been shown to be more successful in selected patients with PVR, ${ }^{1+}$ and its use as a primary treatment for giant retinal tears achieves a high rate of retinal reattachment. ${ }^{13}$ In addition, after vitrectomy, silicone oil can be removed relatively easily and this may reduce the incidence of complications. ${ }^{12}$

The development of cataract in patients with complicated retinal detachments may be related to chronic retinal detachment or to multiple surgical procedures. ${ }^{2+26} \mathrm{We}$ therefore excluded analysis of those patients who developed retinal redetachment. Our results demonstrate that opacities continue to develop even after removal of the oil in many patients. The longer the oil remained in the eye, the greater the risk of progressive lens opacities subsequent to its removal. No patient in this series failed to develop opacities if the oil was present for longer than 10 weeks. Gonvers reported a high rate of cataract formation after oil removal $(78 \%)^{14}$ and our figures are in agreement with his.

We confirmed that glaucoma in patients following silicone oil injection occurs mostly in aphakic patients. ${ }^{2-4}$ Some patients developed glaucoma in the first weeks after oil injection. These patients were almost all aphakic and had a broad or superior peripheral iridectomy. Since early glaucoma in aphakes with silicone oil appears to be commonly due to pupil block, it may be altogether prevented by an inferior peripheral iridectomy. ${ }^{27}$ This has now become routine practice at this hospital but was not at the time that the patients in this series underwent surgery.
Roussat and Ruellan ${ }^{21}$ found that glaucoma in patients with silicone oil in situ was difficult to treat either medically or surgically, but successful filtering procedures after silicone oil removal in a small number of cases have been reported. ${ }^{1+15}$ Some aphakic patients responded simply to the removal of the oil, these usually having had high pressures from the time of oil injection. Of the patients who underwent removal of silicone oil for the treatment of glaucoma, with or without drainage surgery, most were controlled or had IOPs less than $30 \mathrm{mmHg}$ postoperatively. With time several of the patients in this series have required further glaucoma surgery, such as the revision of the drainage tube or cyclocryotherapy, and it may be that the eventual number of patients whose intraocular pressures remain controlled in the long term would decrease.

Leaver et al. ${ }^{16}$ reported on three patients with keratopathy whose corneae showed evidence of clearing after oil removal, while Gonvers ${ }^{14}$ reported on four cases that developed corneal dystrophy after removal of silicone oil and required keratoplasty. Both Cairns and Anand ${ }^{15}$ and Beekhuis et al. ${ }^{28}$ described patients whose clear corneae became decompensated after removal of silicone oil. In this series keratopathy was not a frequent indication for removal of silicone oil. Patients with keratopathy at the time of oil removal were mostly aphakic, and the silicone oil had remained in the eyes for a relatively long time (mean 56.2 weeks). The cornea cleared completely only in the patients who had corneal oedema associated with high intraocular pressure.

None of the eyes with clear corneae at the time of oil removal developed corneal decompensation after the oil was removed. Most were phakic and the corneal endothelium was protected from direct contact with silicone oil. In aphakic eyes or in phakic patients with oil in the anterior chamber the oil was in situ for a relatively short time.

In the animal model silicone oil in the anterior chamber appears to cause loss of endothelial cells, resulting in corneal oedema ${ }^{28}{ }^{29}$ However, most of our patients whose anterior chambers were filled with silicone oil retained remarkably clear corneae. It has been suggested that a large silicone oil bubble in the anterior chamber prevents access of aqueous to the stroma, ${ }^{2430}$ and thus corneal oedema does not develop even in the presence of a reduced endothelial cell count; rather, in this situation corneal thinning may develop. Corneal oedema may increase when the oil is removed and aqueous gains access to the corneal stroma. On the other hand the clearing of the mild central oedema in some of our patients after oil removal might be explained by the spreading out of the residual endothelial cells to replace the damaged cells. ${ }^{31}$ 
All three patients who had a penetrating keratoplasty with removal of silicone oil maintained a clear graft. It has been reported that corneal grafts performed after oil removal have remained clear but were not as successful when the oil was left in situ. ${ }^{112 x}$

In conclusion, we found that the occurrence of lens opacities or their progression is common after the removal of silicone oil, even after a short tamponade of a few weeks. Glaucoma and keratopathy can be prevented by removing the silicone. However, such complications are relatively infrequent in silicone filled eyes, and, if they do occur, they can be successfully treated once the silicone has been removed. Furthermore, the procedure of silicone oil removal carries a definite ocular morbidity, ${ }^{17}$ and it may be argued that this procedure is carried out only in eyes affected by glaucoma and keratopathy or in eyes at risk. Further studies are needed to identify such high risk patients.

We are indebted to $\mathrm{R} \mathrm{K}$ Blach, $\mathrm{R} \mathrm{J}$ Cooling, $\mathrm{P}$ K Leaver, and D Macleod for allowing us to include their patients in our study. We thank Mr Peter Leaver for his comments on the manuscript and $\mathrm{Mr} P$ Clark for statistical assistance. This work was supported in part by the Friends of Moorfields, and A G Casswell holds a Friends of Moorfields Research Fellowship.

\section{References}

1 Cibis PA, Becker B, Okun E, Canaan S. The use of liquid silicone in retinal detachment surgery. Arch Ophthalmol 1962; 68: $590-9$.

2 Leaver PK, Grey RHB, Garner A. Silicone oil injection in the treatment of massive preretinal retraction. II. Late complications in 93 eyes. Br J Ophthalmol 1979; 63: 361-7.

3 Okun E. Intravitreal surgery utilising liquid silicone. Trans Pacific Coast Oto-ophthalmol Soc 1968; 49: 141-59.

4 Haut J, Ullern M, Chermet M, Van Effenterre G. Complications of intraocular injections of silicone combined with vitrectomy. Ophthalmologica 1980; 180: 29-35.

5 Kanski JJ, Daniel R. Intravitreal silicone injection in retinal detachment. Br J Ophthalmol 1973; 57: 542-5.

6 Cockerham WD, Schepens CL, Freeman HM. Silicone injection in retinal detachment. Arch Ophthalmol 1970; 83: 704-12.

7 Lee P, Donovan RH, Mukai N, Schepens CL, Freeman HM. Intravitreous injection of silicone-an experimental study. I. Clinical picture and histology of the eye. Ann Ophthalmol 1969; 1: $15-25$.

8 Mukai N, Lee P, Schepens CL. Intravitreous injection of silicone-an experimental study. II. Histochemistry and electron microscopy. Ann Ophthalmol 1972; 4: 273-87.

9 Mukai N, Lee P, Oguri M, Schepens CL. A long-term evaluation of silicone retinopathy in monkeys. Can J Ophthalmol 1975; 10: 391-402.

10 Chuo N, Wang W-J, Albert DM, Schepens CL. Intravitreous silicone injection. Histopathological findings in a human eye after 12 years. Arch Ophthalmol 1983; 101: 1399-401.

11 Ober RR, Blanks JC, Ogden TE, Pickford M, Minkler DS, Ryan SJ. Experimental retinal tolerance to liquid silicone. Retina 1983 ; 3: $77-85$.

12 Gonvers M. Temporary use of intraocular silicone oil in the treatment of detachment with massive periretinal proliferation. Ophthalmologica 1982; 184: 210-8.

13 Leaver PK, Cooling RJ, Feretis EB, Lean JS, Mcleod D. Vitrectomy and fluid/silicone-oil exchange for giant retinal tears: results at six months. BrJ Ophthalmol 1984; 68: 432-8.

14 Gonvers $\mathrm{M}$. Temporary silicone oil tamponade in the management of retinal detachment with proliferative vitreoretinopathy. Am J Ophthalmol 1985; 100: 239-45.

15 Cairns JD, Anand N. Combined vitrectomy, intraocular microsurgery and liquid silicone in the treatment of proliferative vitreo-retinopathy. Aust J Ophthalmol 1984; 12: 133-8.

16 Leaver PK, Grey RHB, Garner A. Complications following silicone oil injection. In: Streiff EB, ed. Modern Problems in Ophthalmology. Basel: Karger, 1979; 20: 290-4.

17 Casswell AG, Gregor ZJ. Silicone oil removal. II. Operative and postoperative complications. BrJ Ophthalmol 1987; 71: 898-902.

18 Lean JS, Leaver PK, Cooling RJ, Mcleod D. Management of complex retinal detachments by vitrectomy and fluid/silicone exchange. Trans Ophthalmol Soc UK 1982; 102: 203-5.

19 Leaver PK, Lean JS. Management of giant retinal tears using vitrectomy and silicone-oil/fluid exchange. A preliminary report. Trans Ophthalmol Soc UK 1981; 101: 189-91.

20 Schepens CL. Retinal detachment and allied disease. Philadelphia: Saunders, 1983: 2.

21 Roussat B, Ruellan YM. Traitement du décollement de rétine par vitrectomie et injection d'huile de silicone. J Fr Ophtalmol 1984; 7: 11-8.

22 McCuen BW, Landers MB, Machemer R. The use of silicone oil following failed vitrectomy for retinal detachment with advanced proliferative vitreoretinopathy. Ophthalmology 1985; 92: 1029-34.

23 Machemer R, Laqua $\mathrm{H}$. A logical approach to the treatment of massive periretinal proliferation. Ophthalmology 1978; 85: 584-93.

24 Schepens CL. Discussion of rationale of surgical procedures. In: Pryett RC, Regan CGJ, eds. Retina congress. New York: Appleton-Century-Crofts, 1974: 316.

25 Watzke RC. Silicone retinopoiesis for retinal detachment: a long-term clinical evaluation. Arch Ophthalmol 1967; 77: 185-90.

26 Scott JD. Lens changes in retinal detachment. Trans Ophthalmol Soc UK 1979; 99: 241-3.

27 Ando F. Intraocular hypertension resulting from pupillary block by silicone oil. Am J Ophthalmol 1985; 99: 87-8.

28 Beekhuis WH, von Rij G, Zivojnovic R. Silicone keratopathy: indications for keratoplasty. BrJ Ophthalmol 1985; 69: 247-53.

29 Sternberg P, Hatchell DL, Foulks GN, Landers MB. The effect of silicone oil on the cornea. Arch Ophthalmol 1985; 103: 90-4.

30 Waring GO, Bourne WM, Edelhauser HF, Kenyon KR. The corneal endothelium. Normal and pathological structure and function. Ophthalmology 1982; 89: 531-90.

31 Kerr Muir M, Sherrard ES. Semin Ophthalmol in press.

Accepted for publication 20 November 1986. 